\title{
An Intelligent Control Fire Dam System for Mine Roadway
}

\author{
Zheng Xuezhao, a, Wang $\mathrm{Hu}^{2, \mathrm{~b}}$, Wen $\mathrm{Hu}^{3, \mathrm{c}}$, Guo Junn ${ }^{4,}$, Qin Kang ${ }^{5, \mathrm{e}}$
}

\section{Wu Wenqing ${ }^{6, f}$}

${ }^{1}$ No. 58, Yanta Road, Xi'an, Shaanxi Province,China; ${ }^{2}$ No. 58, Yanta Road, Xi'an, Shaanxi Province,China; ${ }^{3}$ No. 58, Yanta Road, Xi'an, Shaanxi Province,China; ${ }^{4}$ No. 58, Yanta Road, Xi'an, Shaanxi Province,China; ${ }^{5}$ No. 58, Yanta Road, Xi'an, Shaanxi Province;6No. 58, Yanta Road, Xi'an, Shaanxi Province,China

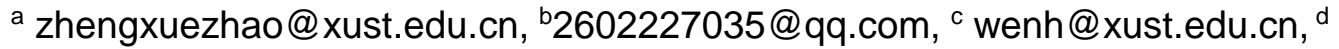
252038127@qq.com, e956721403@qq.com, ${ }^{\mathrm{f}} 1250806541 @ q q . c o m$

Keywords:mine roadway; self - walking; intelligent control; airbag; fire dam

Abstract: The fast sealing technology of mine roadway is an effective method to isolate spontaneous combustion zone, poisonous and noxious gas source or gas accumulation area by establishing effective sealed wall quickly. Aiming at the problems of poor sealing effect, cumbersome operation, difficult construction and low automation level of traditional fire dam, a kind of intelligent control fire dam system of mine roadway is developed by using the combination of airbag fire dam and intelligent control trolley. Based on the analysis of the rapid sealing technology of mine currently, this paper emphatically introduces the concrete design scheme and the applicable conditions of the intelligent control fire dam in mine roadway, which aiming at improving the ability of our country to deal with mine disasters and reducing the serious economic loss of mine caused by fire and the threat to the personnel.

\section{Introduction}

The geological conditions of coal mine in China are complex and changeable. With the increase of mining depth, all kinds of disaster accidents have been occurred frequently ${ }^{[1]}$, which poses a serious threat to mine safety production. Underground coal mine is a complex production environment full of dangerous sources. In the five disasters of mine, gas explosion accidents and fire accidents have the highest occurring rate, which seriously threatening the safety of coal mines and the lives of miners ${ }^{[2]}$. After the disaster, the rapid construction of underground temporary fire dam is an effective way to prevent twice gas explosion accidents and fire spread. In the past, it is necessary for the professionals close to the dangerous area to carry on the airtight construction. The construction time is long and the work load is big, which often cannot play the good airtight function. If the airtight construction personnel do not understand the environmental condition in the local area of the roadway, the safety of the personnel will be threaten. The rapid and effective establishment of the fire dam to isolate the spontaneous combustion zone, harmful gas source or gas accumulation area is an effective means to prevent the expansion of the disaster ${ }^{[3]}$.

With the rapid development of intelligent control technology, sensing technology and network communication technology, it provides various technical support for developing an intelligent control fire dam system for mine roadway. In this paper, a kind of intelligent control fire dam of mine roadway can be controlled by remote control, which can temporarily block local gas accumulation or overrun area and quickly seal the fire spot in high temperature. It can be 
applied to rapid temporary airtight of underground mine, seal tunnel leakage and fire zone, control the fire and smoke, etc. It is of great practical significance to improve the disaster resilience of mine, prevent the expansion of disaster accidents, and reduce the serious economic loss and casualties caused by fire in mine.

\section{Fast sealing technology and its limitation in mine roadway}

In order to prevent coal seam spontaneous combustion, harmful gas diffusion or gas explosion and affect the safety of production, fire dam will be established to isolate the spontaneous combustion zone, harmful gas source or gas accumulation area. At present, the sealing technology commonly used at home and abroad has a closed plate ${ }^{[4]}$, polyurethane spraying sealing ${ }^{[5]}$, spray glue and lightweight concrete block sealing ${ }^{[6]}$, rapid colloidal explosion-proof sealing ${ }^{[7]}$, parachute-type sealing ${ }^{[8]}$, airbag type sealing ${ }^{[9]}$ and so on. Case study by four kinds of typical fast sealing - coal ash heightening hydrogel material, brick concrete sealing, airbag type fast sealing and umbrella type sealing, this paper introduces the sealing principle and the limitation. The performance is shown in table 1.

Brick concrete sealing: interdict airflow and fire zone through establishing fire dam with dressed stone and masonry reinforced concrete in the roadway. When the wall thickness reaches to a certain extent, it can withstand a certain explosion shock wave. However, due to the quantity and weight for forming fire dam by dressed stone and masonry is relatively large, for well mining coal mine, the transportation is relatively difficult with high cost, large labor and long operation time, which is very unfavorable for the personnel safety of underground workers. On the other hand, dressed stone and masonry reinforced concrete are rigid material. When on the mine roof, the cushioning performance of fire dam is very poor and very easy to destroy the fire dam.

Coal ash heightening hydrogel material: use coal ash discharged by power plant boiler; with high water speed coagulation material as binder; select sealing location; form the forming facility of fill sealing by the collapsible form, monomer column, stake and back plate; send the high water coal ash material into the template for filling and sealing operation in the downhole by mud pump. However, the construction workload is large and the sealing time is long.

Airbag type fast sealing: the principle of airbag type fast sealing is in the fast-sealing roadway area, using compressed air or inert gas, blowing the air bag to make it close to the surrounding roadway contour to achieve the purpose of sealing roadway. Compared with other sealing methods, the airbag type fast sealing has the advantages of short erection time and small air leakage rate. However, the stability is poor, which limits the development of the technology.

Umbrella-type sealing: umbrella-type sealing is similar with airbag-type airtight. The system mainly includes airbag body, skirt edge and traction rope. The airbag body expands rapidly under the action of high pressure dynamic inflatable source. When the pressure rises to a certain value, the airbag body of umbrella sealing cuts off the wind jointly with the surrounded mine roadway and main body of sealing. Parachute-type sealing has the characteristics of good stability and short closed time but the air leakage rate is relatively large. It also has relatively large dependency on the direction of airflow and pressure. It can only be used in the wind side, which has large limitations. 
Table 1 Comparison of four typical fast sealing performances

Sealing mode Forming time of sealing Temperature resistance Duration of sealing Air leakage rate

$\begin{array}{lllll}\begin{array}{l}\text { brick concrete sealing } \\ \text { coal ash heightening } \\ \text { hydrogel sealing }\end{array} & \begin{array}{l}\text { more than } 60 \mathrm{~min} \\ \text { more than } 60 \mathrm{~min}\end{array} & \begin{array}{l}\text { more than } 600^{\circ} \mathrm{C} \\ \text { more than } 500^{\circ} \mathrm{C}\end{array} & \begin{array}{l}\text { more than } 10 \mathrm{~d} \\ \text { more than } 10 \mathrm{~d}\end{array} & \begin{array}{l}\text { less than } 5 \% \\ \text { less than } 5 \%\end{array} \\ \begin{array}{l}\text { umbrella type sealing } \\ \text { airbag type sealing }\end{array} & \begin{array}{l}\text { more than } 10 \mathrm{~min} \\ \text { less than } 10 \mathrm{~min}\end{array} & \begin{array}{l}\text { less than } 300^{\circ} \mathrm{C} \\ \text { less than } 300^{\circ} \mathrm{C}\end{array} & \begin{array}{l}\text { more than } 1 \mathrm{~d} \\ \text { more than } 1 \mathrm{~d}\end{array} & \begin{array}{l}\text { more than } 5 \% \\ \text { less than } 5 \%\end{array}\end{array}$

It can be seen from the table that the traditional brick-concrete fast fire dam has the obvious superiority in the temperature-resistant performance, the duration, the air leakage rate and so on. However, due to the long constructing time, it does not favor the construction personnel safety; The umbrella type and the airbag type fast fire dam have short construction time, which reduces the airflow to the fire area and the threat of secondary explosion in the fire area and ensure the safety of the operators; compared with parachute-type sealing and airbag-type sealing technology, the gas-filled sealing has short construction time and small air leakage rate, which has great development prospect.

\section{Design scheme of intelligent control fire dam in mine roadway}

\section{Structure design of intelligent control fire dam}

In order to ensure the safety of personnel, the intelligent control fire dam system designed in this paper includes the ground device and the downhole device, and achieves fast sealing effect by remote control. The ground device consists of an industrial computer and a quick junction box. The downhole device consists of an intelligent control trolley and a intelligent control fire dam. The ground device and the downhole device are connected through a communication and power supply cable. The overall connection relationship is shown in Figure 1.

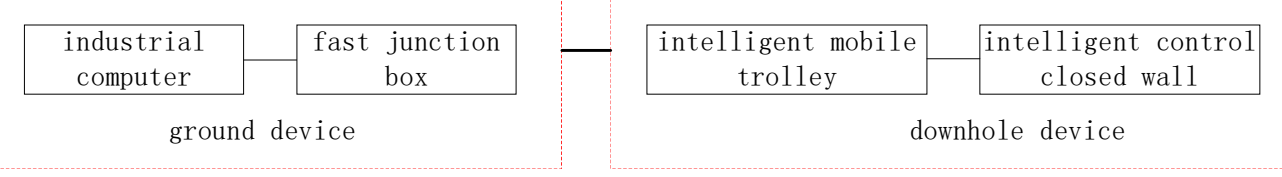

Figure 1 General layout of intelligent fire dam

The main structure of the intelligent fire dam system is the intelligent control fire dam and trolleys. Among them, the intelligent control trolley includes hydraulic devices, explosion-proof cameras, trolleys, and quick wiring devices; the intelligent control fire dam includes high-pressure nitrogen cylinders, solenoid valves, and jet aerators, gas relief valves, intelligent control panels, environmental parameter sensors, inclinometers, walls, and airbags mounted around walls. Figure 2 and Figure 3 show the system structure of intelligent control fire dam and profile map of fire dam. 


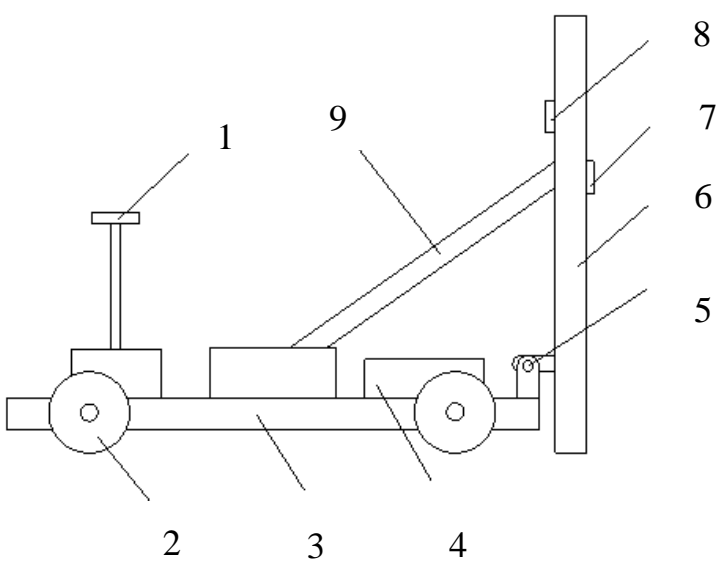

1-explosion-proof camera, 2-trolley tire, 3- trolley body, 4- trolley drive, 5- connection between trolley and wall, 6-airbag fire dam body, 7-outside environmental parameter sensor, 8-inside environmental parameters sensor, 9-hydraulic device

Figure 2 System structure of intelligent control fire dam

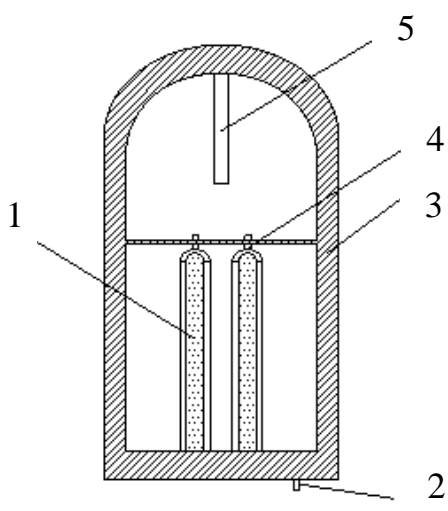

1-high-pressure nitrogen bottle, 2-gas relief valve, 3-airbag, 4-solenoid valve, 5-inclinometer Figure 3 Profile map of fire dam

\section{System design of intelligent control fire dam}

The intelligent control fire dam control system designed in this paper includes an airbag control device and a self-propelled control device of fire dam. The airbag control device includes a first controller and a gas cylinder. The gas cylinder is provided with a first controller connected to the airbag control device, inflatable valve and air release valve. The input end of the first controller is connected with a parameter input unit, a gas detection component inside the wall, a gas detection component inside and outside the wall, and a pressure sensor; the self-propelled control device of fire dam includes a first communication module, a first controller, a walking motor controlled by the first controller, a hydraulic machine driver, and a second communication module. The system instructions are controlled by client-specific software. The system chart of intelligent fire wall control system is shown in Figure 4. 


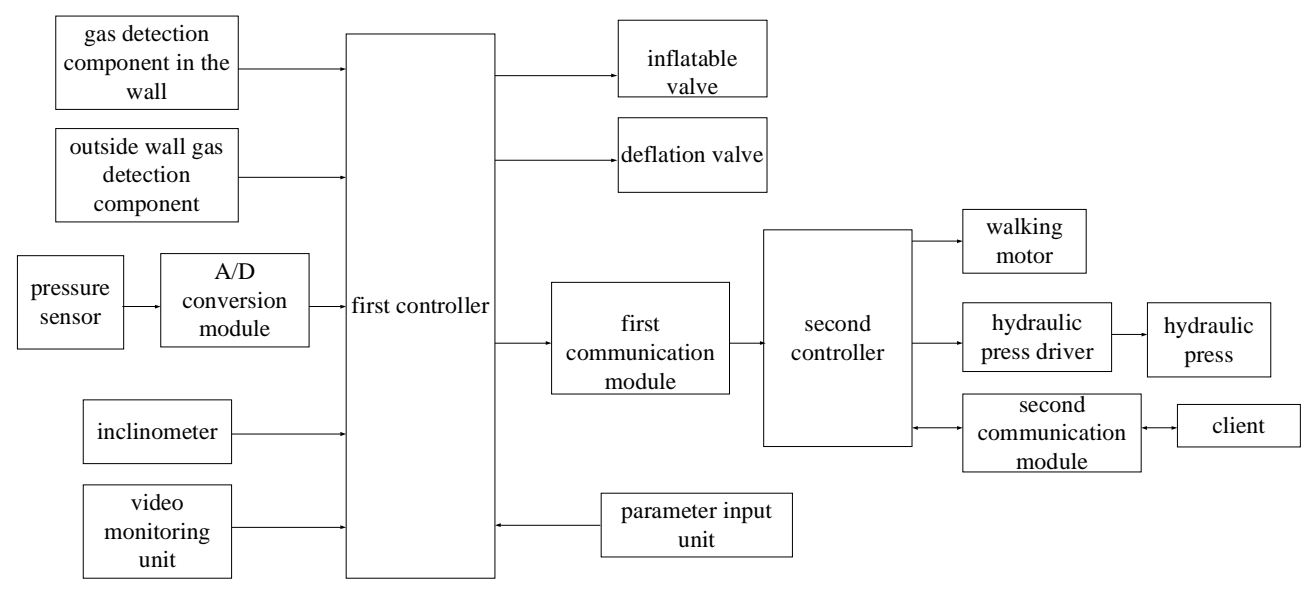

Figure 4 The chart of intelligent fire wall control system

\section{Model selection of airbag}

The airbag is rapidly inflated after being inflated by a high-pressure nitrogen gas cylinder and closely fits around the roadway. Under the action of the mine fire pressure or the ventilation pressure $\mathrm{Q}$, the airbag pressure-receiving volume decreases, the internal pressure $\mathrm{N}$ increases, and the friction force between airbag and the surrounding roadway is increased. The force of the airbag in the roadway is shown in the Figure5.

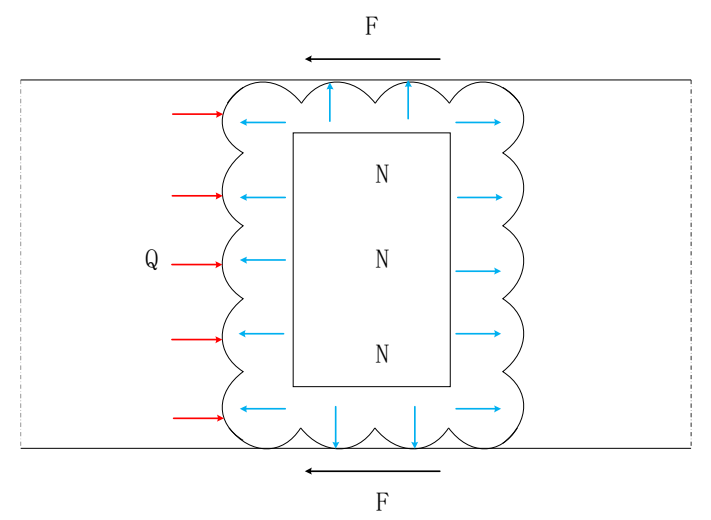

Figure 5 Schematic diagram of force analysis of airbag in roadway

The inner pressure of the airbag is determined by the following formula:

$$
\mathrm{N}>\mathrm{QS} / \mathrm{KBL}
$$

In the formula: $\mathrm{N}$ - airbag pressure, $\mathrm{Pa} ; \mathrm{Q}$ - fire pressure or ventilation pressure, $\mathrm{Pa}$; $\mathrm{S}$-roadway area, $\mathrm{m}^{2} ; \mathrm{k}$ - the coefficient of friction between airbag and roadway around, dimensionless; $\mathrm{B}$ - airbag thickness, $\mathrm{m}$; L-roadway perimeter, $\mathrm{m}$.

Fire air pressure or ventilation pressure of mine is usually small. In the case of a small airbag thickness, it can be fitted with the surrounding roadway and isolated from the fire zone. The material used for the airbag is reinforced plastic cloth. The cloth consists of three layers. In the middle is a base cloth woven with high-strength nylon yarn. The two edges of the airbag are composed of a PVC plastic film with anti-static, flame-retardant and sealing properties, which can reach the sealing effect of complicated roadway.

\subsection{Working principle of intelligent control fire dam}

The basic working principle of the existing airbag sealing is to set up obstacles in the roadway to block the flow of air, and finally achieve the purpose of blocking fresh air from entering the fire zone and spreading toxic and harmful gases to the non-fire zone ${ }^{[10]}$. The intelligent control fire dam system designed in this paper has made a lot of improvements and innovations on the basis of the original. When a fire or toxic gas concentration exceeds the limit, 
the downhole device is controlled remotely through a laptop computer to make it travel in the roadway. The signal detected by the camera and the sensor is transmitted to the well by the self-discharge line carried along with the system so that the ground personnel can keep track of the situation within the roadway. When approaching the disaster area, quickly and remotely start the hydraulic device installed on the trolley so that the fire dam is kept perpendicular to the trolley. The position of the trolley is properly adjusted by the feedback signal from the laser inclinometer so that the fire dam is always maintained in a vertical state. And then remotely control the solenoid valve installed on the high-pressure nitrogen gas bottle opening quickly. The airbag around the fire dam is quickly attached to the roadway wall under the action of high-pressure nitrogen. The airbag and the wall of the roadway are remotely judged the fit situation by the environmental parameter sensors installed on both sides of the wall. When a sensor mounted on a sealed wall detects that the environmental parameters on both sides of the sealed wall are normal, the remote control opens the airbag relief valve and removes the trolley from the roadway to complete the fast and temporary sealing.

\section{The features and application conditions of intelligent control fire dam}

\section{The features of intelligent control fire dam}

At present, there are limitations in the application of mine fire dam. The development of fast fire dam which are suitable for mine rescue is mainly on airbag-type rapid sealing - Good rapid prototyping, closed and stable, wear-resistant anti-static, explosion-proof performance, simple and quick operation, safe and reliable and the rapid establishment of sealed walls in coal mines, effectively control the expansion of sudden changes in the shortest possible time, ensure the life safety of ambulance personnel and the orderly conduct of rescue and relief work, and increase the success rate of rescue. The intelligent control fire dam system designed in this paper has the following characteristics compared with the existing temporary fire dam:

(1) The fire dam system is easy to operate, which has a fast construction speed. It uses a high-pressure nitrogen cylinder with a volume of $8 \mathrm{~L}$, a nitrogen filling pressure of $12 \mathrm{MPa}$, and a high-speed jet aerator. Generally, it takes only 2.5 minutes to complete the temporary sealing, and the air leakage rate is less than 5\%. If no external damage, it can be maintained for more than 24 hours.

(2) The material used for the airbag has the characteristics of antistatic, flame retardant, and good sealing performance to meet the sealing effect of complex roadways.

(3) The fire dam system overcomes many problems. For example, the existing airbag-type sealing is easy to collapse, which resulting in poor sealing effect, and can be repeatedly used with low cost. It can be used as rescue equipment of mine emergency in various rescue teams and reduce casualties and economic losses.

(4) The fire dam system has the functions of remote control, monitoring and supervising. The computer-specific software can clearly observe the conditions in the roadway and provide detailed information for the next relief of mine disaster, and ensure the safety of personnel to the greatest extent.

\section{Application condition of intelligent control fire dam}

As the sealing type of this design is mainly on the airbag, the material of the airbag is reinforced with plastic cloth. Although the surface is coated with fire-retardant material, in order to ensure the normal operation of the airbag, the fireproof temperature cannot exceed $300^{\circ} \mathrm{C}$. When a stable temporary seal is established, the conditions inside the fire dam can be monitored at any time. If the disaster inside the roadway cannot be controlled, other emergency measures 
should be taken immediately.

\section{Conclusions}

An intelligent control fire dam system for mine roadway has the function of real-time monitoring and display of downhole image and environmental parameters, and can quickly complete the task of fast and temporary sealing in the disaster area environment that people cannot reach, and quickly isolate the spontaneous combustion area, harmful gas source, and gas accumulation area to prevent the disaster spreading to ensure the safety of personnel; the system has a remote intelligent control function. The signal is reliably transmitted to the ground through the communication and power supply cable so that the relevant personnel can understand the underground disaster situation in time. The intelligent control of the fire dam system has a good sealing effect, and small air leakage rate. If no external damage, it can be used repeatedly; new airbag sealing device is used folds and skirt structure, which has a good sealing effect for irregular rough roadway.

\section{References:}

[1]Wen Hu, Guo Jun, Jin Yongfei, et al. "Research progress and trend of evaluation of thermal and dynamic disasters in mines in China"[J]. Coal Mine Safety, 2016, 47(3):172-174.

[2]Song Hongyu, Li Zhixian. "Research on the possibility evaluation technology of gas explosion accidents in coal mines"[J]. Mining Safety and Environmental Protection, 2009, 36(05): 78-80.

[3] Yin Jun, Wen Xuelei, Zhang Shitao. "Study on key technologies of intelligent control fast sealing airbag” [J]. Coal Mining Machinery, 2015, 36(10): 92-93.

[4] Song Xianming. "Research and application of fast sealing technology for mine rescue" [D]. Xi'an University of Science and Technology, 2013

[5]Xu Sheng. "Application of polyurethane foam spray plugging wind technology in coal roadway"[J]. Energy Technology and Management, 2006(01):45-46.

[6]Li Wanjie. "Characteristics and applications of new type of fast sealing”[J]. Coal Mine Safety, 2002(11):35-37.

[7]Luo Zhenmin, Deng Jun, Wen $\mathrm{Hu}$, et al. "A new type of fire dam of rapid colloidal anti-explosion for coal mines"[J]. Coal Mine Safety, 2007, 38(9):34-35.

[8]Wang Guochao, Deng Guohong, Dai Xiaoping, et al. "Research on high-temperature fast sealing of parachute air-inflated'[J]. Mining Safety and Environmental Protection, 2000, 27(6):5-6.

[9]Zhou Fubao, Liu Yingke, Zhang Rengui. "Research on a new type of automatic closure equipment of airbag" [J]. Journal of China University of Mining \& Technology, 2008, 37(5):604-607.

[10]Ma Li, Ni Xinghua, Song Xianming, Cai Zhouquan. "Study on the airbag sealing technology for mine rescue"[J]. Shandong Coal Science and Technology, 2010(05):145-146. 